Molecules 2004, 9, 1-10

molecules

ISSN 1420-3049

http://www.mdpi.org

\title{
Hexachloroacetone as a Precursor for a Tetrachloro-substituted Oxyallyl Intermediate: [4+3] Cycloaddition to Cyclic 1,3-Dienes
}

\author{
Baldur Föhlisch* and Stefan Reiner \\ Institut für Organische Chemie der Universität Stuttgart, Pfaffenwaldring 55, D-70569 Stuttgart, \\ Germany; Fax: (internat) + 49-711/6854269 \\ * Author to whom correspondence should be addressed; E-mail: baldur.foehlisch@po.uni-stuttgart.de
}

Received: 27 November 2003; in revised form: 11 January 2004; Accepted: 12 January 2004 /

Published: 31 January 2004

Abstract: The enol phosphate 2,2-dichloro-1-(trichloromethyl)ethenyl diethyl phosphate (1), easily available by a Perkow reaction between hexachloroacetone and triethyl phosphite, reacts with sodium trifluoroethoxide/trifluoroethanol in the presence of cyclic 5-membered 1,3-dienes to furnish $\alpha, \alpha, \alpha^{\prime}, \alpha^{\prime}$-tetrachloro-substituted[3.2.1]bicyclic ketones 2. A [4+3] cycloaddition of a tetrachloro-oxyallyl intermediate is postulated.

Keywords: Ketones, Solvolysis, Phosphorus, Allylic compounds, Cycloaddition.

\section{Introduction}

A tetrachloro-substituted oxyallyl intermediate has been generated from pentachloroacetone (PCA) and utilized for many [4+3] cycloaddition reactions with 1,3-dienes and furans [1-5]. On preparation of PCA by chlorination of acetone, hexachloroacetone (HCA) is formed as a by-product in varying amounts [6]. Instead of disposing of the perchlorinated ketone, it seemed desirable to us to also utilize HCA for the generation of the tetrachloro-oxyallyl species. Moreover, HCA, a useful reagent, is also commercially available at present or may be prepared easily $[7,8]$.

Standard metal reductions, e.g. with $\mathrm{Zn} / \mathrm{Cu}$ couple, do not promise good selectivity in [4+3] cycloadditions because the tetrachloro-substituted cycloadducts formed are expected to be dehalogenated further. 


\section{Results and Discussion}

Checking the literature, we became aware of the reaction between HCA and trialkyl phosphites, resulting in enol phosphates, e.g. 2,2-dichloro-1-(trichloromethyl)ethenyl diethyl phosphate (1) [9], which has been investigated because of its biological activity as a repellent against insects [10]. This dehalogenation, an example of the Perkow reaction [11], represents a selective reduction of HCA as well.

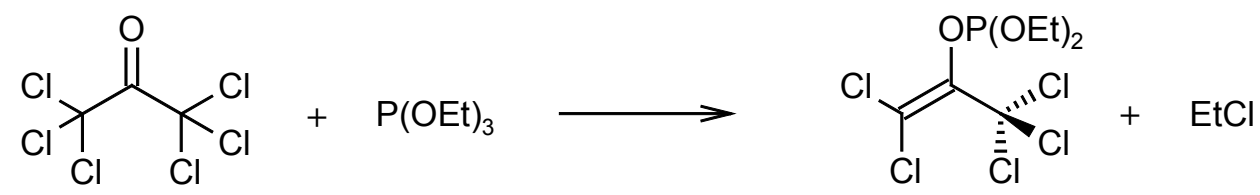

The enol phosphate $\mathbf{1}$ has an allylic structure with an oxygen atom at the central carbon atom (C-2), and chloride leaving groups at one terminus. Therefore, we expected that ionization of this allyl chloride should be possible, leading eventually to a tetrachloro-oxyallyl intermediate. The ionization should be promoted by use of appropriate solvent systems, such as polyfluorinated alcohols [1,3].

Indeed, on treatment of 1 with sodium 2,2,2-trifluoroethoxide/2,2,2-trifluoroethanol (NaTFE/TFE) in the presence of furan, sodium chloride was formed, and the oxabicycle $\mathbf{2 a}$ that is known to be formed by [4+3] cycloaddition of the oxyallyl intermediate generated from PCA could be isolated in over $50 \%$ yield $[1,3]$.

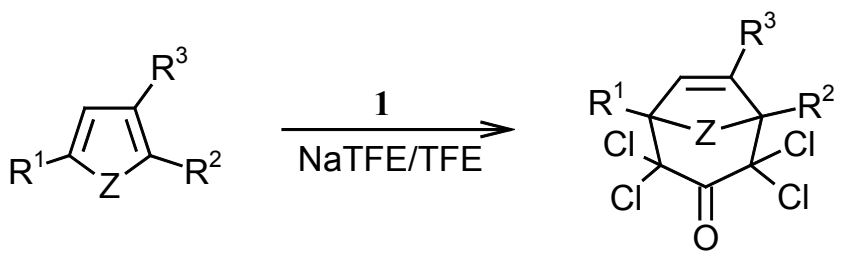

\begin{tabular}{l|llll} 
2 & $\mathrm{R}^{1}$ & $\mathrm{R}^{2}$ & $\mathrm{R}^{3}$ & $\mathrm{Z}$ \\
\hline a & $\mathrm{H}$ & $\mathrm{H}$ & $\mathrm{H}$ & $\mathrm{O}$ \\
b & $\mathrm{H}$ & $\mathrm{H}$ & $\mathrm{H}$ & $\mathrm{CH}_{2}$ \\
c & $\mathrm{H}$ & $\mathrm{H}$ & $\mathrm{H}$ & $\mathrm{C}<\left(\mathrm{CH}_{2}\right)_{2}$ \\
d & $\mathrm{CH}_{3}$ & $\mathrm{H}$ & $\mathrm{H}$ & $\mathrm{O}$ \\
e & $\mathrm{CH}_{3}$ & $\mathrm{CH}_{3}$ & $\mathrm{H}$ & $\mathrm{O}$ \\
f & $\mathrm{H}$ & $\mathrm{CH}_{2}=\mathrm{CHCH}_{2} \mathrm{CH}_{2}$ & $\mathrm{CH}_{3}$ & $\mathrm{O}$ \\
g & $\mathrm{H}$ & $\mathrm{CH}_{2}=\mathrm{C}\left(\mathrm{CH}_{3}\right) \mathrm{CH}_{2} \mathrm{CH}_{2}$ & $\mathrm{CH}_{3}$ & $\mathrm{O}$
\end{tabular}


In order to examine the by-products, we ran the reaction in the absence of furan: diethyl $(2,2,2-$ trifluoroethyl) phosphate (3), 2,2,2-trifluoroethyl 2,3,3-trichloroprop-2-enoate (6), and 2,2,2trifluoroethyl dichloroacetate (9) could be detected. The latter two products are known to arise from a Favorskii rearrangement and haloform cleavage, respectively, of PCA (5) [5]. The presence of phosphate ester 3 is in accordance with the mechanism shown in Scheme 1, initiated by a nucleophilic attack of trifluoroethoxide anion on the phosphorus atom of $\mathbf{1}$. The perchlorinated enolate ion $\mathbf{4}$ can be protonated to form PCA (5). Obviously the main reaction channel is ionization, forming the tetrachloro-oxyallyl intermediate 8 that then combines with furan in a [4+3] cycloaddition.

The peak of the trifluoroethyl phosphate $\mathbf{3}$ was also found in the gas chromatograms of the reaction mixtures with furan (i.e. as by-product of 2a) and all the 1,3-dienes described below. Due to the polarity and volatility of the ester 3 [12] the cycloadducts 2 could be separated and isolated without any difficulties by ether extraction from the water/TFE phase, and work-up by distillation, crystallization or chromatography, if necessary.

Scheme 1. Base-induced alcoholysis of 2,2-dichloro-1-(trichloromethyl)ethenyl diethyl phosphate (1), for $\mathrm{R}=\mathrm{CF}_{3} \mathrm{CH}_{2}$.
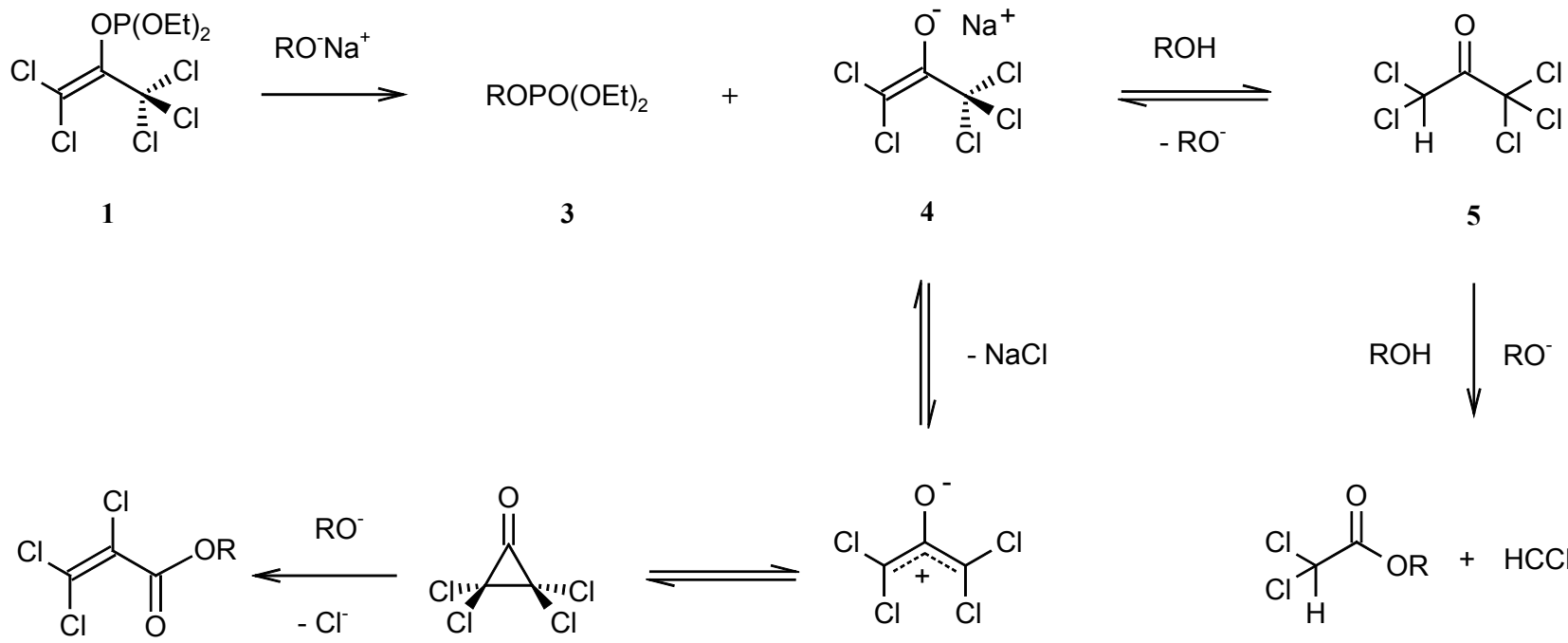<smiles></smiles>

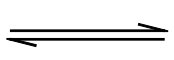<smiles>[O-]C(Cl)=C(Cl)Cl</smiles><smiles>[R]OC(=O)C(Cl)Cl</smiles>

6<smiles>O=C(C(Cl)Cl)C(Cl)Cl</smiles>

From the Scheme it is evident that one equivalent of sodium trifluoroethoxide is needed for generating the oxyallyl intermediate. However, the consecutive side reactions would consume more base. Therefore we monitored the progress of the reaction by checking the $\mathrm{pH}$ with indicator paper. A 
slightly alkaline state of the reaction mixture $(\mathrm{pH} 7-8)$ was observed after 18 hours at ambient temperature.

This cyclocondensation protocol was also applied to cyclopentadiene and spiro[2.4]hepta-4,6diene, which furnished the carbobicycles $\mathbf{2 b}$ and $\mathbf{2 c}$, respectively. The latter as yet unreported tricyclic spirocompound had been previously prepared by us in $45 \%$ yield from PCA using sodium 2,2,3,3tetrafluoropropoxide in 2,2,3,3-tetrafluoropropanol [3]. With triethylamine and lithium perchlorate/diethylether [2], the cyclocondensation between PCA and the spirodiene resulted in a very dark product mixture (see also the reaction with furan [3]). It was difficult to separate the tricycle 2c from the black, resinous side products that were formed in substantial amounts.

Whereas the cheap dienes cyclopentadiene and furan were made to react in excess, as co-solvents, the other 'dienes' were used in equimolar amounts or in a slight excess. 2-Methylfuran, 2,5dimethylfuran, 2-(but-3-enyl)-3-methylfuran, and 3-methyl-2-(3-methylbut-3-enyl)furan gave the wellknown oxabicycles 2d-g [4] in yields ranging between 40 and 50\% (Table 1). In all cases, the yields of the [4+3] cycloadducts were lower than with the PCA procedure, but the preparations were not optimized.

Table 1. Tetrachloro-substituted [3.2.1]bicycles (2) from 1, and PCA, respectively

\begin{tabular}{lcccc}
\hline Educt & Product & $\begin{array}{c}\text { Yield [\%] } \\
\text { from 1 }\end{array}$ & $\begin{array}{c}\text { Yield [\%] } \\
\text { from PCA }\end{array}$ & Ref. \\
\hline Furan & $\mathbf{2 a}$ & 54 & 57 & {$[1,3]$} \\
Cyclopentadiene & $\mathbf{2 b}$ & 39 & 57 & {$[4]$} \\
Spiro[2.4]hepta-4,6-diene & $\mathbf{2 c}$ & 45 & 49 & {$[\mathrm{a}]$} \\
2-Methylfuran & $\mathbf{2 d}$ & 44 & 66 & {$[4]$} \\
2,5-Dimethylfuran & $\mathbf{2 e}$ & 47 & 68 & {$[4]$} \\
2-(But-3-enyl)-3-methylfuran & $\mathbf{2 f}$ & 51 & 88 & {$[4]$} \\
3-Methyl-2-(3-methylbut-3-enyl)furan & $\mathbf{2 g}$ & 45 & 87 & {$[4]$} \\
\hline
\end{tabular}

[a] This work

Since TFE is an expensive solvent, we tried to replace it by ethanol, using sodium ethoxide as the base. However, not a trace of cycloadduct 2a was found upon reaction of $\mathbf{1}$ in the presence of furan. This further supports the unique properties of TFE.

A further approach towards ionization of 1 was made: a Lewis acid might assist in pulling off an 'allylic' chloro atom, possibly resulting in an $O$-phosphorylated oxyallyl intermediate. However, when 1 was allowed to react with boron trifluoride diethyl etherate and an excess of furan, no cycloadduct $\mathbf{2 a}$ could be detected. Other, more 'chlorophilic' Lewis acids were not investigated. 


\section{Conclusions}

Our intention in these studies, utilization of hexachloroacetone as precursor for the generation and cycloaddition of oxyallyl intermediates, was verified in principle. It is true that the yields of the [4+3] cycloadducts are mediocre; but the preparations were not optimized. Possibly a more thorough investigation would result in better yields. The authors will not continue these investigations and would therefore welcome further research by other groups. Moreover, analogous derivatives of pentachloropropen-2-ol should be examined, e.g. pentachloro-2-(trimethylsiloxy)propene that can be prepared by the similar reaction of HCA with tris(dimethylamino)phosphane and chlorotrimethylsilane [13].

\section{Acknowledgements}

We thank the analytical and spectroscopic service of the Institute of Organic Chemistry for gas chromatograms, spectra, and elemental analysis, especially Jochen Rebell (NMR). Oliver Schwarz and Uwe Wustmann made experimental contributions.

\section{Experimental}

\section{General}

IR spectra were recorded on a Perkin-Elmer 457 instrument. NMR instruments: Bruker AC 250, for 62.9 MHz ${ }^{13} \mathrm{C}-\mathrm{NMR}$, and $101.26 \mathrm{MHz}$ for ${ }^{31} \mathrm{P}-\mathrm{NMR}$ spectra, respectively, Varian $\mathrm{T} 60$, for $60 \mathrm{MHz}$ ${ }^{1} \mathrm{H}-\mathrm{NMR}$ spectra and a Bruker ARX 500 spectrometer was used for the $500 \mathrm{MHz}{ }^{1} \mathrm{H}-\mathrm{NMR}$ and 125.8 $\mathrm{MHz}{ }^{13} \mathrm{C}$-NMR of compound 2c. For ${ }^{1} \mathrm{H}-\mathrm{NMR}$ and ${ }^{13} \mathrm{C}-\mathrm{NMR}, \mathrm{CDCl}_{3}$ was used as solvent and TMS as internal standard. $85 \% \mathrm{H}_{3} \mathrm{PO}_{4}$ was used as an external standard for ${ }^{31} \mathrm{P}-\mathrm{NMR}$. Analytical TLC: precoated sheets, Polygram Sil G / UV 254 (silica), or Polygram N / UV 254 (alumina), distributed by Macherey-Nagel \& Co, Düren, Germany; detection by UV extinction. Preparative column chromatography: silica gel $60(63-200 \mu \mathrm{m}$ or 40-63 $\mu \mathrm{m})$, distributed by Macherey-Nagel \& Co. MPLC on LiChroprep Si 60 (Merck), particle size 15-25 $\mu \mathrm{m}$, elution with petroleum ether (PE) / ethyl acetate (EA) mixtures. Dry PE was distilled (b.p. $40-65^{\circ} \mathrm{C}$ ). EA was dried over calcium chloride, distilled, and kept dry over $4 \AA$ molecular sieves. Dichloromethane was dried by refluxing over powdered calcium hydride and distilled. Melting points were determined with a Büchi 510 apparatus (Büchi Laboratoriumstechnik AG, Flawil / Switzerland) and are uncorrected. Elemental analyses were performed by the service of the Institut für Organische Chemie, University of Stuttgart. Hexachloroacetone (HCA) was prepared after Bugrova [6,7d]. Pentachloroacetone (PCA) was commercially available at that time (Aldrich); for a preparation, see ref.[6]. For sodium trifluoroethoxide/trifluoroethanol (NaTFE/TFE) reagent, see ref.[4]. Furan, 2-methylfuran and triethyl phosphite were commercially available products (Fluka, Merck). The furans were shaken with dilute 
$\mathrm{KOH}$, dried over $\mathrm{KOH}$ pellets, and distilled from $\mathrm{KOH}$ pellets before use. The other dienes were prepared according to given literature procedures.

\section{2,2-Dichloro-1-(trichloromethyl)ethenyl diethyl phosphate (1)}

This educt was prepared after ref.[9] and showed b.p. $115-120^{\circ} \mathrm{C} / 0.002$ Torr (lit.: $131-132^{\circ} \mathrm{C} / 0.8$ Torr. [9]) Caution: Many enol phosphates are strongly toxic on contact and inhalation ("Viele Enolphosphate sind starke Berührungs- und Atmungsgifte") [14]. - The following spectral data were determined: ${ }^{1} \mathrm{H}-\mathrm{NMR}(60 \mathrm{MHz}): \delta=1.40\left(\mathrm{dt},{ }^{3} J_{\mathrm{H}, \mathrm{H}}=7-8 \mathrm{~Hz},{ }^{4} J_{\mathrm{H}, \mathrm{P}}=1 \mathrm{~Hz}, 6 \mathrm{H}, \mathrm{CH}_{3}\right), 4.30$ (quintet, $\left.{ }^{3} J_{\mathrm{H}, \mathrm{H}} \cong{ }^{3} J_{\mathrm{H}, \mathrm{P}}=7-8 \mathrm{~Hz}, 4 \mathrm{H}, \mathrm{CH}_{2}\right) ;{ }^{13} \mathrm{C}\left\{{ }^{1} \mathrm{H}\right\} \mathrm{NMR}(62.9 \mathrm{MHz}): \delta=16.1\left(\mathrm{~d},{ }^{3} J_{\mathrm{C}, \mathrm{P}}=7.0 \mathrm{~Hz}, \mathrm{CH}_{3}\right), 65.6$ $\left(\mathrm{d},{ }^{2} J_{\mathrm{C}, \mathrm{P}}=6.25 \mathrm{~Hz}, \mathrm{CH}_{2}\right), 91.6\left(\mathrm{~s}, \mathrm{CCl}_{3}\right), 122.4\left(\mathrm{~d},{ }^{3} J_{\mathrm{C}, \mathrm{P}}=8.7 \mathrm{~Hz}, \mathrm{P}-\mathrm{O}-\mathrm{C}=C\right), 143.1\left(\mathrm{~d},{ }^{2} J_{\mathrm{C}, \mathrm{P}}=11.2 \mathrm{~Hz}\right.$, P-O-C $=\mathrm{C}) ;{ }^{1} \mathrm{H}$-coupled ${ }^{13} \mathrm{C}-\mathrm{NMR}(62.9 \mathrm{MHz}): \delta=16.1\left(\mathrm{qd},{ }^{1} J_{\mathrm{C}, \mathrm{H}}=127.5 \mathrm{~Hz},{ }^{2} J_{\mathrm{C}, \mathrm{P}}=6.9 \mathrm{~Hz}, \mathrm{P}-\mathrm{O}-\right.$ $\left.\mathrm{CH}_{2}-\mathrm{CH}_{3}\right), 65.6\left(\mathrm{td},{ }^{1} J_{\mathrm{C}, \mathrm{H}}=149.3 \mathrm{~Hz},{ }^{2} J_{\mathrm{C}, \mathrm{P}}=4.4 \mathrm{~Hz}, \mathrm{P}-\mathrm{O}-\mathrm{CH}_{2}-\mathrm{CH}_{3}\right), 91.6\left(\mathrm{~s}, \mathrm{CCl}_{3}\right), 122.4\left(\mathrm{~d},{ }^{3} J_{\mathrm{C}, \mathrm{P}}=\right.$ $8.5 \mathrm{~Hz}, \mathrm{P}-\mathrm{O}-\mathrm{C}=C), 143.2\left(\mathrm{~d},{ }^{1} J_{\mathrm{C}, \mathrm{P}}=11.3 \mathrm{~Hz}, \mathrm{P}-\mathrm{O}-C=\mathrm{C}-\right)$; ${ }^{31} \mathrm{P}-\mathrm{NMR}\left(101.26 \mathrm{MHz}, \mathrm{CDCl}_{3}, 85 \% \mathrm{H}_{3} \mathrm{PO}_{4}\right.$ as external standard): $\delta=-7.12$ (quintet, ${ }^{3} J_{\mathrm{H}, \mathrm{P}}=8 \mathrm{~Hz}, P-\mathrm{O}-\mathrm{CH}_{2}$ ).

Reaction of 1 with Sodium 2,2,2-trifluoroethoxide in 2,2,2-Trifluoroethanol - Diethyl (2,2,2-trifluoroethyl) phosphate (3), 2,2,2-Trifluoroethyl 2,3,3-trichloroprop-2-enoate (6) and 2,2,2-Trifluoroethyl dichloroacetate $(\mathbf{9})$

A solution of sodium 2,2,2-trichloroethoxide (NaTFE) in 2,2,2-trifluoroethanol (TFE) (10 mL, c = $1 \mathrm{~mol} / \mathrm{L}$ ) was prepared and cooled in an ice bath. With magnetic stirring, 1 (3.66 g, $10 \mathrm{mmol})$ was added dropwise over 30 minutes. The ice bath was removed, and the mixture stirred for 1 day at room temperature. Then water $(15 \mathrm{~mL})$ was added, and the layers separated. The aqueous layer was extracted with diethyl ether $(4 \times 10 \mathrm{~mL})$, and the combined organic solutions dried with sodium sulfate. A gas chromatogram (OV 101 column, $80 \rightarrow 220{ }^{\circ} \mathrm{C}, 8 \mathrm{~K} / \mathrm{min}$ ) showed peaks of 6 and 9 that were assigned by coinjection with authentic substances [5]. The solution was concentrated in a rotary evaporator; the liquid residue was dissolved in $\mathrm{CDCl}_{3}$ and examined by ${ }^{31} \mathrm{P}-\mathrm{NMR}$ spectroscopy. A signal at $\delta=-1.55$ (septet, $J=8 \mathrm{~Hz}$, singlet with a decoupled spectrum) was consistent with the chemical shift reported for 3 [12]. A further signal at $\delta=-7.26$ (quintet, $J=8.0 \mathrm{~Hz}$ ) corresponded to educt $\mathbf{1}$, thus indicating that the reaction time was too short.

\section{2,2,4,4-Tetrachloro-8-oxabicyclo[3.2.1]oct-6-en-3-one (2a).}

Method a) 2,2-Dichloro-1-(trichloromethyl)ethenyl diethyl phosphate (1) (3.66 g, $10 \mathrm{mmol})$ was mixed with furan $(10 \mathrm{~mL}, 156.3 \mathrm{mmol})$ and cooled in an ice-bath. A solution of sodium 2,2,2trichloroethoxide (NaTFE) in 2,2,2-trifluoroethanol (TFE) $(10 \mathrm{~mL}, \mathrm{c}=1 \mathrm{~mol} / \mathrm{L})$ was added dropwise with magnetic stirring, over 5 minutes. The ice bath was removed, and the mixture stirred for $18 \mathrm{hrs}$ at room temperature; a test with $\mathrm{pH}$ indicator paper indicated that over this time the $\mathrm{pH}$ had dropped from 13-14 to a weakly basic reaction ( $\mathrm{pH} 8-9)$. Then, water $(20 \mathrm{~mL})$ was added, and the layers separated. The aqueous layer was extracted with diethyl ether $(4 \times 10 \mathrm{~mL})$, and the combined organic solutions 
dried with sodium sulfate. After filtration, the solution was concentrated in a rotary evaporator, and the remaining liquid was put for $1 \mathrm{~d}$ into a refrigerator $\left(6^{\circ} \mathrm{C}\right)$ whereupon crystallization occured. The supernatant liquid was separated by means of a pipette, and the crystalline mass washed with petroleum ether $(4 \times 1 \mathrm{~mL})$. The colourless, crystalline solid was dried in vacuo; yield $1.29 \mathrm{~g}, 49 \%$. The mother liquor and the washings were combined, concentrated, and distilled in a Kugelrohr at 100 ${ }^{\circ} \mathrm{C} / 0.002$ Torr. The distillate was subjected to gravity column (length $50 \mathrm{~cm}$, diameter $2.7 \mathrm{~cm}$ ) chromatography on silica. Elution with PE/dichloromethane (9:1) gave more colourless crystals $(0.13$ g, 5\%). Total yield of the product (2a) amounted to $1.42 \mathrm{~g}(54 \%)$, with m.p. $85-87^{\circ} \mathrm{C}$ (ref.[1]: m.p. $\left.88-89{ }^{\circ} \mathrm{C}\right)$. The IR and ${ }^{1} \mathrm{H}$ NMR $(60 \mathrm{MHz})$ spectrum were in agreement with those obtained from earlier preparations [1-4].

Method b) Prepared from furan $(10 \mathrm{~mL}, 156.3 \mathrm{mmol})$ and 1 (3.66 g, $10 \mathrm{mmol})$. The product was purified by crystallization from the minimal amount of PE. Yield $1.35 \mathrm{~g}(52 \%)$ as colourless crystals with m.p. $85-87^{\circ} \mathrm{C}$ (ref.[1]: m.p. $88-89{ }^{\circ} \mathrm{C}$ ). The IR and ${ }^{1} \mathrm{H}$ NMR $(60 \mathrm{MHz})$ spectrum were in agreement with those from earlier preparations [1-4].

\section{2,2,4,4-Tetrachlorobicyclo[3.2.1]oct-6-en-3-one (2b).}

To a mixture of 1 (3.66 g, $10 \mathrm{mmol})$ and freshly prepared cyclopentadiene $(6.60 \mathrm{~g}, 100 \mathrm{mmol})$, a solution of sodium 2,2,2-trichloroethoxide (NaTFE) in 2,2,2-trifluoroethanol (TFE) (10 mL, c $=1$ $\mathrm{mol} / \mathrm{L}$ ) was added with magnetic stirring at room temperature. After ca. 5 min the mixture became turbid, and a white precipitate $(\mathrm{NaCl})$ was formed. The progress of the reaction was monitored by GLC. After $4 \mathrm{~h}$ the peak of the educt 1 had disappeared. Water $(50 \mathrm{~mL})$ was added to the mixture, and the layers separated. The aqueous layer was extracted with tert-butylmethyl ether $(3 \times 10 \mathrm{~mL})$. The organic solutions were combined and dried with magnesium sulfate. After filtration, the solvent was removed in a rotary evaporator, and the residual reddish liquid (4.22 g) subjected to adsorptive filtration over silica (80 g). Elution was made with PE/EA (20:1). The solvent was removed in a rotary evaporator; a gas chromatogram of the remaining yellow liquid (1.64 g) indicated the presence of $\mathbf{2 b}$ and dicyclopentadiene (coinjection with authentic substances). The oil was distilled in a Kugelrohr at $110{ }^{\circ} \mathrm{C} / 0.001$ Torr to give a white solid (1.37 g) with m.p. $43-45^{\circ} \mathrm{C}$ (2b, ref.[4]: $\left.47-48{ }^{\circ} \mathrm{C}\right)$. Both GLC and thin layer chromatogram (PE/EA 20:1) showed that the substance was still contaminated. Therefore it was recrystallized from the minimal amount of n-pentane. The mother liquor of the crystals (0.77 g) was subjected to MPLC on Merck LiChroprep Si 60, eluting with PE/EA (190:1) to give a further $0.24 \mathrm{~g}$ of $\mathbf{2 b}$. Total yield $1.01 \mathrm{~g}(39 \%)$. The IR and ${ }^{1} \mathrm{H}$ NMR (60 MHz) spectrum were in agreement with those from an earlier preparation [4].

\section{2,2,4,4-Tetrachloro-spiro(bicyclo[3.2.1]oct-6-ene-8,1'-cyclopropane)-3-one (2c)}

Method a) Prepared from spiro[2.4]hepta-4,6-diene [15d] (0.92 g, $10 \mathrm{mmol})$ and 1 (3.66 g, 10 $\mathrm{mmol})$ according to the procedure described above. Adsorptive filtration over silica with PE/EA (20:1) followed by crystallization from n-pentane $(40 \mathrm{~mL})$ gave $2 \mathrm{c}(1.28 \mathrm{~g}, 45 \%)$ as colourless crystals with m.p. $103-104^{\circ} \mathrm{C}$. 
Method b) From PCA with sodium 2,2,3,3-tetrafluoropropanolate/2,2,3,3-tetrafluoropropanol [16]: Spiro[2.4]hepta-4,6-diene[15c], (1.84 g, $20 \mathrm{mmol})$ and PCA (4.61 g, $20 \mathrm{mmol})$ were mixed and cooled in an ice-bath. A solution of sodium 2,2,3,3-tetrafluoropropanolate/2,2,3,3-tetrafluoropropanol $(20 \mathrm{~mL}, \mathrm{c}=1 \mathrm{~mol} / \mathrm{L})$ was added dropwise, with magnetic stirring. After $3 \mathrm{~h}$, diethyl ether $(150 \mathrm{~mL})$ was added, and the precipitated sodium chloride removed by filtration and washed with ether. The liquid was concentrated in a rotary evaporator. The remaining solid was dissolved in PE/EA (19:1) (10 $\mathrm{mL}$ ) and filtrated over silica $(80 \mathrm{~g})$ in a $40 \times 2 \mathrm{~cm}$ column, eluting with $500 \mathrm{~mL}$ of PE/EA. The fractions that contained the cycloadduct $(\mathbf{2 c})$, were concentrated and the residue crystallized from diethyl ether. One obtained $2.81 \mathrm{~g}(49 \%)$ of $2 \mathrm{c}$ as colourless needles with m.p. 104.0-104.5 ${ }^{\circ} \mathrm{C}$.

Method c) With lithium perchlorate/diethylether/ triethylamine: Dry lithium perchlorate (32 g, 0.3 mol) was dissolved in dry diethylether $(250 \mathrm{~mL})$ and mixed with triethylamine (42 $\mathrm{mL}, 0.3 \mathrm{~mol})$. Spiro[2.4]hepta-4,6-diene [15c] (13.8 g, $0.15 \mathrm{~mol})$ and PCA (34.5 g, $0.15 \mathrm{~mol})$ were added dropwise with rapid magnetic stirring. After $12 \mathrm{~h}$ water $(100 \mathrm{~mL})$ was added, and the layers separated. The aqueous layer was extracted with diethyl ether $(3 \times 50 \mathrm{~mL})$. The combined organic solutions were dried with magnesium sulfate, filtrated and concentrated in vacuo. The residue crystallized as a dark mass that was purified by flash-chromatography on silica $(180 \mathrm{~g}$, column $80 \times 4 \mathrm{~cm})$ with PE/EA (19:1) yielding $6.93 \mathrm{~g}(16 \%)$ of needles with a faint brownish colour and m.p. $104-104.5{ }^{\circ} \mathrm{C}$; IR (KBr): 3080 , 3000, $2955(\mathrm{CH}), 1790,1755$ (s), $1735(\mathrm{C}=\mathrm{O}), 1425,1325,1255,1190,1100 \mathrm{~cm}^{-1}$; ${ }^{1} \mathrm{H}-\mathrm{NMR}$ (500 $\mathrm{MHz}): \delta=0.57\left(, \mathrm{t}^{*}\right.$, line distance $8 \mathrm{~Hz}$ [17], 2H, $\left.\mathrm{CH}_{2}\right) ; 1.62\left(, \mathrm{t}^{\star *}\right.$, line distance $8 \mathrm{~Hz}$ [17], 2H, $\left.\mathrm{CH}_{2}\right)$; 2.87 (s, 2H, 1-H, 5-H); 6.52 (s, 2H, 6-H, 7-H); ${ }^{13} \mathrm{C}-\mathrm{NMR}(125.8 \mathrm{MHz}): \delta=10.1\left(\mathrm{CH}_{2}\right), 13.2\left(\mathrm{CH}_{2}\right)$, 31.9 (C-8), 61.1 (C-1, C-5), 86.2 (C-2, C-4), 138.4 (C-6, C-7), 187.3 (C-3); Anal. For $\mathrm{C}_{10} \mathrm{H}_{8} \mathrm{Cl}_{4} \mathrm{O}$ (286.0): calcd. C 42.00, H 2.82, Cl 49.59; found C 42.13, H 2.87, Cl 49.47.

\section{1-Methyl-2,2,4,4-tetrachloro-8-oxabicyclo[3.2.1]oct-6-en-3-one (2d)}

Prepared from 2-methylfuran (1.00 g, $12.2 \mathrm{mmol})$ and 1 (3.66 g, $10 \mathrm{mmol})$. The crude product was purified by adsorptive filtration over silica with PE/dichloromethane (9:1). Colourless crystals with m.p. 54.0-54.5 ${ }^{\circ} \mathrm{C}$ (lit.[4]: 53-54 ${ }^{\circ} \mathrm{C}$ ); yield $1.20 \mathrm{~g}$ (44\%). The IR and ${ }^{1} \mathrm{H}-\mathrm{NMR}$ (60 MHz) spectrum were in agreement with those from an earlier preparation [4].

\section{1,5-Dimethyl-2,2,4,4-tetrachloro-8-oxabicyclo[3.2.1]oct-6-en-3-one (2e)}

Prepared from 2,5-dimethylfuran [18] (1.20 g, $12.5 \mathrm{mmol})$ and 1 (3.66 g, $10 \mathrm{mmol})$. The crude product was purified by adsorptive filtration over silica with $\mathrm{PE} /$ dichloromethane (9:1). Colourless crystals with m.p. $112-113{ }^{\circ} \mathrm{C}$ (lit.[4] m.p. $\left.111-112^{\circ} \mathrm{C}\right)$; yield $1.35 \mathrm{~g}(47 \%)$. The IR and ${ }^{1} \mathrm{H}-\mathrm{NMR}(60$ $\mathrm{MHz}$ ) spectrum were in agreement with those from an earlier preparation [4]. 
1-(But-3-enyl)-2,2,4,4-tetrachloro-7-methyl-8-oxabicyclo[3.2.1]oct-6-en-3-one (2f)

Prepared from 2-(but-3-enyl)-3-methylfuran [19] (1.36 g, $10 \mathrm{mmol})$ and 1 (3.66 g, $10 \mathrm{mmol})$. The crude product was purified by adsorptive filtration over silica with PE/EA (20:1) and crystallization from n-hexane $(10 \mathrm{~mL})$. Colourless crystals with m.p. $62{ }^{\circ} \mathrm{C}$ (ref.[4]: m.p. $67^{\circ} \mathrm{C}$ ); yield $1.68 \mathrm{~g}(51 \%)$. The IR and ${ }^{1} \mathrm{H}-\mathrm{NMR}(60 \mathrm{MHz})$ spectrum were in agreement with those from an earlier preparation [4].

2,2,4,4-Tetrachloro-7-methyl-1-(3-methylbut-3-enyl)-8-oxabicyclo[3.2.1]oct-6-en-3-one (2g)

Prepared from 3-methyl-2-(3-methylbut-3-enyl)furan [20] (1.50 g, $10 \mathrm{mmol})$ and 1 (3.66 g, 10 mmol). The crude product was crystallized from PE/EA $(20: 1)(10 \mathrm{~mL})$ to give $1.55 \mathrm{~g}(45 \%)$ of colourless crystals with m.p. $102{ }^{\circ} \mathrm{C}$ (lit.[4]: m.p. 101-102 ${ }^{\circ} \mathrm{C}$ ). The IR and ${ }^{1} \mathrm{H}-\mathrm{NMR}(60 \mathrm{MHz})$ spectrum were in agreement with those from an earlier preparation [4].

\section{References and Notes}

1. Föhlisch, B.; Gehrlach, E.; Herter, R. Angew. Chem. 1982, 94, 144; Angew. Chem. Suppl. 1982, 241-248; Angew. Chem. Internat. Edit. Engl. 1982, 21, 137.

2. Herter, R.; Föhlisch, B. Synthesis 1982, 976-978.

3. Föhlisch, B.; Gehrlach, E.; Geywitz, B. Chem. Ber. 1987, 120, 1815-1824.

4. Sendelbach, S.; Schwetzler-Raschke, R.; Radl, A.; Kaiser, R.; Henle, G. H.; Korfant, H.; Reiner, S.; Föhlisch, B. J. Org. Chem. 1999, 64, 3398-3408.

5. Föhlisch, B.; Korfant, H.; Meining, H.; Frey, W. Eur. J. Org. Chem. 2000, 1335-1344.

6. Föhlisch, B.; Zinser, H. Org. Prep. Procedures Int., submitted.

7. a) Edwards, E. G.; Evans, D. P.; Watson, H. B. J. Chem. Soc. 1937, 1942-1946; b) Gerrard, W.; Howe, B. K. J. Chem. Soc. 1955, 505-510; c) Geiger, M.; Usteri, E.; Gränacher, C. Helv. Chim. Acta 1951, 34, 1335-1344; d) Bugrova, L. V.; Rudnev, G. K.; Khristich, A. I.; Radchenko, V. I.; Mishchenko, L. F. Zh. Prikl. Khim. (Leningrad) 1973, 46, 1529-1533; J. Appl. Chem. USSR 1973, 2, 1627-1631 (Engl. Trans1) [Chem. Abstr. 1973, 79, 91499q].

8. For some uses, see: a) Kadaba, P. K.; Edwards, J. O. J. Org. Chem. 1960, 25, 1432-1433; b) Grant, F. W.; Cassie, W. B. J. Org. Chem. 1960, 25, 1433-1434; c) Holy, A.; Smrt, J.; Šorm, E. Coll. Czech. Chem. Commun. 1965, 30, 3309-3319; d) Rudavskii, V. P.; Khaskin, I. G. Ukr. Khim Zh. 1967, 33, 391-394 [Chem. Abstr. 1967, 67, 63963v]; e) Panetta, C. A.; Casanova, T. G. J. Org. Chem. 1970, 35, 2423-2425; f) Migaichuk, V.; Khaskin, I. G. Zh. Prikl. Khim. (Leningrad) 1977, 50, 2599-2602; J. Appl. Chem. USSR 1977, 50, 2471-2473 (Engl. Transl); g) Laskovics, F. M.; Schulman, E. M. J. Am. Chem. Soc. 1977, 99, 6672-6677; h) Magid, R. M.; Talley, B. G.; Souther, S. K. J. Org. Chem. 1981, 46, 824-825; i) Freedlander, R. S.; Bryson, T. A.; Dunlap, R. B.; Schulman, E. M.; Lewis, C. A. J. Org. Chem. 1981, 46, 3519-3521; j) Talley, J. J. Tetrahedron Lett. 1981, 22, 823-826; k) Bew, C.; Otero de Joshi, V.; Gray, J.; Kaye, P. T.; Meakins, G. D. J. Chem. Soc. Perkin Trans. 1, 1982, 945-948; 1) Hrubiec, R. T.; Smith, M. B. 
Synth. Commun. 1983, 13, 593-599; m) Hrubiec, R. T.; Smith, M. B. J. Org. Chem. 1984, 49, 431-435.

9. Wiley, D. W.; Simmons, H. E. J. Org. Chem.1964, 29, 1876-1879.

10. Nikonorov, K. V.; Neklesova, I. D.; Gutylev, E. A.; Kudrina, M. A.; Nikonenko, V. A.; Mertsalova, F. F.; Anisimova, N. N.; Iraidova, I. S.; Egorova, N. V.; Lisanova, I. A. Zh. Obshch. Khim. 1974, 44, 1267-1272; J. General Chem. USSR 1974, 44, 1245-1250 (Engl. Transl.).

11. a) Perkow, W. Chem. Ber. 1954, 87, 755-758; b) For an overview, see, e.g. Krauch, H.; Kunz, W. Reaktionen der organischen Chemie, 6th edition (Kunz, W.; Nonnenmacher, E., Eds.), Hüthig Verlag: Heidelberg, 1997; pp 634-636, and the literature cited therein.

12. Timperley, C. M.; Morton, I. J.; Waters, M. J.; Yarwood, J. L. J. Fluorine Chem. 1999, 96, 95100.

13. Filonenko, L. P.; Bespal'ko, G. K.; Marchenko, A. P.; Pinchuk, A. M. Zh. Obshch. Khim. 1987, 57, 2320-2324; J. Gen. Chem. USSR 1987, 57, 2074-2078 [Chem. Abstr. 1988, 109, 129086f] - However, the required reagents would be more expensive.

14. Hesse, G. In Methoden der Organischen Chemie (Houben-Weyl); Bayer, O.; Kropf, H.; Hesse, G., Eds.; Thieme: Stuttgart, 1978; Vol. 6/1d, pp 130-133, and the literature cited therein.

15. a) Levina, R. Ya.; Mezentsova, N. N.; Lebedev, O. V. Zh. Obshch. Khim. 1955, 29, 1097-1101; J. Gen. Chem. USSR. 1955, 25, 1055-1057 (Engl. Transl.); b) Hallam, B. F.; Pauson, P. L. J. Chem. Soc. 1958, 646-650; c) Alder, K.; Ache, H. J.; Flock, F. H. Chem. Ber. 1960, 93, 18881895; d) Kunitake, T.; Ochiai, T. Macromol. Synth. 1985, 9, 61-63.

16. Prepared by Uwe Wustmann in the course of the Organisch-chemisches Praktikum für Fortgeschrittene, February, 8 - May, 8, 1988.

17. The ${ }^{1}$ H-NMR spectrum appears to be deceptively simple, as indicated by a Gauß pulsed recording.

18. Scott, L. T.; Naples, J. D. Synthesis 1973, 209.

19. Kaiser, R.; Föhlisch, B. Helv. Chim. Acta 1990, 73, 1504-1514.

20. a) Firmenich SA (Schulte-Elte, K. H.); Swiss Patent 603614 (6.10.1975) [Chem. Abstr. 1979, 90, P6234j]; b) Kaiser, R. Dissertation, Univ. Stuttgart 1986.

Sample Availability: Samples of compounds $\mathbf{2 a}, \mathbf{2 b}, \mathbf{2 c}, \mathbf{2 d}, \mathbf{2 e}, \mathbf{2} \mathbf{f}$ and $\mathbf{2 g}$ are available from MDPI

(C) 2004 by MDPI (http:www.mdpi.org). Reproduction is permitted for noncommercial purposes. 